\title{
Electrochemical multi-analyte point-of-care perspiration sensors using on-chip three-dimensional graphene electrodes
}

\author{
Meike Bauer $^{1} \cdot$ Lukas Wunderlich $^{1} \cdot$ Florian Weinzierl $^{1} \cdot$ Yongjiu Lei $^{2} \cdot$ Axel Duerkop $^{1} \cdot$ Husam N. Alshareef ${ }^{2}$. \\ Antje J. Baeumner ${ }^{1,3}$ (D)
}

Received: 29 June 2020 / Revised: 26 August 2020 / Accepted: 3 September 2020 / Published online: 28 September 2020

(C) The Author(s) 2020

\begin{abstract}
Multi-analyte sensing using exclusively laser-induced graphene (LIG)-based planar electrode systems was developed for sweat analysis. LIG provides 3D structures of graphene, can be manufactured easier than any other carbon electrode also on large scale, and in form of electrodes: hence, it is predestinated for affordable, wearable point-of-care sensors. Here, it is demonstrated that LIG facilitates all three electrochemical sensing strategies (voltammetry, potentiometry, impedance) in a multi-analyte system for sweat analysis. A potentiometric potassium-ion-selective electrode in combination with an electrodeposited $\mathrm{Ag} / \mathrm{AgCl}$ reference electrode (RE) enabled the detection of potassium ions in the entire physiologically relevant range (1 to $500 \mathrm{mM}$ ) with a fast response time, unaffected by the presence of main interfering ions and sweat-collecting materials. A kidney-shaped interdigitated LIG electrode enabled the determination of the overall electrolyte concentration by electrochemical impedance spectroscopy at a fixed frequency. Enzyme-based strategies with amperometric detection share a common RE and were realized with Prussian blue as electron mediator and biocompatible chitosan for enzyme immobilization and protection of the electrode. Using glucose and lactate oxidases, lower limits of detection of $13.7 \pm 0.5 \mu \mathrm{M}$ for glucose and $28 \pm 3 \mu \mathrm{M}$ for lactate were obtained, respectively. The sensor showed a good performance at different $\mathrm{pH}$, with sweat-collecting tissues, on a model skin system and furthermore in synthetic sweat as well as in artificial tear fluid. Response time for each analytical cycle totals $75 \mathrm{~s}$, and hence allows a quasicontinuous and simultaneous monitoring of all analytes. This multi-analyte all-LIG system is therefore a practical, versatile, and most simple strategy for point-of-care applications and has the potential to outcompete standard screen-printed electrodes.
\end{abstract}

Keywords Laser-induced graphene (LIG) $\cdot$ Point-of-care (POC) $\cdot$ Electrochemical biosensor $\cdot$ Sweat sensor $\cdot$ Health-monitoring platform

\section{Introduction}

Published in the topical collection 2D Nanomaterials for Electroanalysis with guest editor Sabine Szunerits.

Electronic supplementary material The online version of this article (https://doi.org/10.1007/s00216-020-02939-4) contains supplementary material, which is available to authorized users.

Antje J. Baeumner

Antje.Baeumner@ur.de

1 Institute of Analytical Chemistry, Chemo- and Biosensors, University of Regensburg, 93040 Regensburg, Germany

2 Physical Science and Engineering Division, King Abdullah University of Science and Technology (KAUST), Thuwal 23955-6900, Kingdom of Saudi Arabia

3 Department of Biological and Environmental Engineering, Cornell University, Ithaca, NY 14853, USA
The pursuit of developing bio- and chemosensors has long been driven by the realization that these sensors have a powerful potential to address the analytical challenges of onsite, rapid, accurate, simple, and inexpensive detection. Through miniaturization, advancements in biorecognition elements, in coating chemistries, and signal amplification new sensor designs indeed keep proving exactly this potential. A quite current trend in onsite diagnostics seeks to develop wearable sensors not only for clinical diagnostics but also for monitoring of fitness or health state [1]. Here, the miniaturization of electronic components and development of new materials are equally key to advance wearable sensing technology further, as can be evidenced by products ranging from smart watches and wristbands which monitor heartbeat or body temperature through adhesive stickers and screen-printed tattoos to smart 
textiles and contact lenses which are capable of collecting more information than physical vital signs [2].

In the year 1953, Paul di Sant' Agnese et al. published the first article on the detection of cystic fibrosis, a genetic disorder, in context of increased salt concentration in sweat and saliva [3]. Thus, standard test procedures for sodium chloride content in sweat for the immediate detection of the pernicious disease were developed [4]. Sweat also contains many different electrolytes, and other relevant biomarkers like organic acids, metal ions, amino acids, carbohydrates, and vitamins which can be used for drawing conclusions on an individual's health status $[5,6]$. Therefore, besides the sensitivity of the respective detection method for biomarkers in lower concentration ranges, the selectivity of the receptor of the sensor is very important for reliable measurements.

Easy accessibility of sweat at any time with non-invasive collecting methods qualifies sweat as a perfect bio matrix for point-of-care (POC) diagnostics and long-term health monitoring. In general, many factors like environment, activity level, hormones, sympathetic nervous system, and also the individual diet induce perspiration [7]. Eccrine sweat is generated easily over the entire body during physical activities or without exercising in warmer surroundings to regulate the body temperature [8]. For subjects at rest, the sweat rate may be too low for continuous monitoring. However, perspiration can be stimulated simply with heat or by iontophoretic techniques using low electrical currents in combination with agonists like pilocarpine [9]. The analysis of sweat is predestined to be realized in a wearable device for continuous monitoring over a long-term period. As such, reliable glucose level diagnosis by sweat analysis would improve millions of diabetics' daily live routine in a significantly more comfortable way. Studies reveal promising results that the glucose concentration in sweat correlates with blood glucose level and contains no glucose from the environment, albeit studies indicate that blood and interstitial analysis are more reliable $[7,10]$.

A light-weighted and in the best case not noticeable wearable sweat sensor is the favorable way to perform real-time monitoring of body conditions for medical home-care applications or during physical activity. Hydration level, the related electrolyte content, and concentrations of biomolecules give a good overview of the current state of the user's physiological conditions. Potassium ions in general are required for correct nerve transmission and an oversupply as well as a lack thereof can cause several effects up to an abnormal heart rhythm and finally death [11]. An increased electrolyte content in sweat during workout is a direct indication for dehydration [12]. Lactate is an important biomarker for providing information on the oxygen supply in tissue and the entire anaerobic metabolism in muscles. Its concentration in sweat correlates directly with the concentration in blood [13]. If anomalies in these biomarker concentrations are detected in a timely manner, a fast-acting electrolyte or drug intake can prevent malfunctions of the body like muscle cramps or much more threatening consequences occurring due to nutrient deficits [14].

Sweat analysis of such analytes can easily be performed through electrochemical detection. Furthermore, inexpensive mass production possibilities, miniaturization, integration into fluidic systems, and with flexible circuit boards make electrochemical detection a preferred technology for sweat analysis. In fact, carbon-based electrodes dominate the electrochemical point-of-care market [15-20] and advances and better understanding of graphene suggests that it is a highly favorable transducer material.

In search of economic and straight-forward synthesis routes for graphene, Lin et al. reported the new concept of laser-induced graphene (LIG) also termed laser-scribed graphene (LSG) by others [21-23]. It was made from commercial polymers such as polyimide (PI) derivatives in 2014 by exposing those to a computer-controlled $\mathrm{CO}_{2}$ infrared laser which generates $3 \mathrm{D}$ graphene layers under ambient conditions [24]. This economic and reagent-free one-step synthesis of porous graphene on a polymer substrate opened incredible new applications for bioanalytical demands [21-23, 25-28]. It was thus studied here as a material for sweat-based sensing. Of special interest was to demonstrate that an all-LIG sensor can be generated for multi-analyte detection, employing the three important electrochemical detection strategies of voltammetry, potentiometry, and conductometry. Through LIG surface modifications, enzyme-based biosensors for glucose and lactate, an ion-selective chemosensor for potassium ions, and a simple conductometric electrolyte setup were developed. The multi-analyte performance was evaluated to prove that it functioned well within the physiological ranges of all analytes in sweat and was tested on skin and in artificial sweat samples.

\section{Materials and methods}

\section{Chemicals}

All solid and liquid chemicals were of at least analytical grade and purchased from Sigma-Aldrich (Sigma-Aldrich Chemie GmbH, Taufkirchen, Germany), Fluka (Fluka Chemie GmbH, Buchs, Switzerland), VWR (VWR International GmbH, Darmstadt, Germany), Merck (Merck KGaA, Darmstadt, Germany), or Roth (Carl Roth $\mathrm{GmbH}+\mathrm{Co} . \mathrm{KG}$, Karlsruhe, Germany). Chitosan from crab shells (practical grade) was purchased from SigmaAldrich. All reagents were used without further purification. Millipore water was used for preparation of all aqueous solutions. 


\section{Enzymes}

Lactate oxidase (LOx) type II (from Aerococcus viridans, $36.0 \mathrm{U} \mathrm{mg}^{-1}$ powder) was purchased from Hölzel Diagnostika (Hoelzel Diagnostika Handels GmbH, Cologne, Germany). Glucose oxidase (GOx) type VII (from aspergillus niger, $168.8 \mathrm{kU} \mathrm{mg}^{-1}$ powder) was purchased from SigmaAldrich.

\section{Other materials}

Polyimide film with a thickness of $125 \mu \mathrm{m}$ was purchased from CMC Klebetechnik (CMC Klebetechnik GmbH, Frankenthal, Germany). As sweat-collecting pads, the following materials were used: Kimtech Science labor tissues (Kimberly-Clark GmbH, Koblenz, Germany), Whatman ${ }^{\circledR}$ 595 filter paper (Schleicher \& Schuell, Dassel, Germany), gauze (EAZ GmbH, Boeblingen, Germany). Chicken leg was purchased from local supermarkets. Different nail polishes, kitchen towels, and artificial tear fluid were purchased from local drug stores.

\section{Equipment and accessories}

The following equipment with suitable software and accessories were used: Keithley 175 autoranging multimeter (Keithley Instruments Inc., Cleveland, Ohio, USA), CHI 650 A potentiostat (CH Instruments Inc., Austin, Texas, USA), portable bipotentiostats/ galvanostats $\mu$ Stat400 (Metrohm DropSens, Filderstadt, Germany), PalmSens4, and EmStat Blue (PalmSens BV, GA Houten, Netherlands). The handheld plating device was purchased from Conrad Electronic (Conrad Electronic SE, Hirschau, Germany). Commercially available $\mathrm{Ag} / \mathrm{AgCl}$ reference electrodes (Bioanalytical Systems Inc., West Lafayette, IN, USA) and a Pt wire (Goodfellow GmbH, Hamburg, Germany) were used. A Dino Lite digital USB microscope with suitable software DinoCapture 2.0 was used to capture magnified images of the modified LIG electrodes (Dunwell Tech, Inc., Torrance, CA, USA). For all laser-scribing processes, a laser-engraving device VLS 2.30 equipped with a $30 \mathrm{~W} \mathrm{CO}_{2}$ laser $(\lambda=10.6 \mu \mathrm{m})$ from Universal Laser Systems (Universal Laser Systems Inc., Scottsdale, Arizona, USA) was used. For imaging the morphology and structure of the laser-induced graphene, a scanning electron microscope (SEM) LEO 1530 from Zeiss (Carl Zeiss AG, Oberkochen, Germany) was used. Raman spectroscopy was performed with a DXR Raman microscope from Thermo Fisher (Thermo Fisher Scientific GmbH, Dreieich, Germany).

\section{Preparation of solutions and buffers}

1X PBS (phosphate-buffered saline) solution with $\mathrm{pH}$ 7.4, $0.1 \mathrm{~mol} \mathrm{~L}^{-1}$ citrate buffers with $\mathrm{pH} 4$ and $5,0.1 \mathrm{~mol} \mathrm{~L}^{-1}$ phosphate buffers with $\mathrm{pH} 6$ and 7 , and a potassium-free phosphate buffer $\left(0.1 \mathrm{~mol} \cdot \mathrm{L}^{-1}, \mathrm{pH} 7.4\right)$ for the multi-analyte sensor were prepared with and without $1 \mathrm{mmol} \mathrm{L}^{-1}$ glucose. All buffers were stored at $4{ }^{\circ} \mathrm{C}$.

A potassium chloride stock solution with concentration of $1 \mathrm{~mol} \mathrm{~L}^{-1}$ was prepared in water and diluted to concentrations ranging between $1 \cdot 10^{-7}$ and $0.5 \mathrm{~mol} \mathrm{~L}^{-1}$. For the interfering cation study, $\mathrm{MgCl}_{2}, \mathrm{CaCl}_{2}$, and $\mathrm{NaCl}$ stock solutions with a concentration of $0.1 \mathrm{~mol} \mathrm{~L}^{-1}$ were prepared in $10 \mathrm{mmol} \mathrm{L}^{-1}$ $\mathrm{KCl}$ solution and diluted with $10 \mathrm{mmol} \mathrm{\textrm {L } ^ { - 1 }} \mathrm{KCl}$ solution. $\mathrm{AgNO}_{3}$ solution for silver deposition with mass concentration $\beta=400 \mathrm{mg} \mathrm{mL}^{-1}$ in water was prepared. For the $\mathrm{K}^{+}$-selective membrane, two precursor solutions were made: solution A: $270 \mathrm{mg}$ polyvinylchloride (PVC) were dissolved in $2.7 \mathrm{~mL}$ of tetrahydrofuran (THF). Solution B: $520 \mu \mathrm{L}$ dibutyl sebacate (DBS) as plasticizer was mixed with $50 \mu \mathrm{L}$ of valinomycin solution ( $\beta=80 \mathrm{mg} \mathrm{mL}^{-1}$ in methanol). Solution B was continuously stirred while solution A was added. The membrane solution contained $16 \mathrm{mg}$ of valinomycin ionophore per gram PVC. A second PVC cocktail without valinomycin was prepared as described before as protection membrane for the reference electrode. These solutions were stored in a THF atmosphere at $4{ }^{\circ} \mathrm{C}$ and have to be stirred for at least $1 \mathrm{~h}$ at room temperature before use. Nafion solution was mixed with an excess of solid $\mathrm{KCl}$ and continuously stirred to obtain a saturated solution.

For Prussian blue deposition on the working electrode, two $10 \mathrm{mmol} \mathrm{L}^{-1}$ iron (III) salt solutions (precursor solutions) were prepared from $\mathrm{FeCl}_{3}$ and $\mathrm{K}_{3}\left[\mathrm{Fe}(\mathrm{CN})_{6}\right]$. Both were dissolved in a $0.1 \mathrm{~mol} \mathrm{~L}^{-1} \mathrm{HCl}$ solution containing $0.1 \mathrm{~mol} \mathrm{~L}^{-1}$ $\mathrm{KCl}$. Storage at $4{ }^{\circ} \mathrm{C}$ in the dark is recommended. A $0.1 \%$ weight chitosan solution was prepared by dissolving chitosan in $0.1 \mathrm{~mol} \mathrm{~L}^{-1}$ acetic acid. A $100 \mathrm{mmol} \mathrm{L}^{-1}$ hydrogen peroxide (HP) stock solution was freshly prepared before use. Dilution series of HP in buffer ranging between $1 \mu \mathrm{mol} \mathrm{L}{ }^{-1}$ and $10 \mathrm{mmol} \mathrm{L}^{-1}$ were prepared. Synthetic sweat solution according to DIN 53160-2 was prepared by dissolving $5 \mathrm{~g}$ $\mathrm{NaCl}$ and $1 \mathrm{~g}$ urea in $1 \mathrm{~L}$ water and its $\mathrm{pH}$ was adjusted with $1 \% \mathrm{NH}_{4} \mathrm{OH}$ solution to 6.5 . For the biosensor assays, $100 \mathrm{mmol} \mathrm{L}^{-1} \mathrm{D}$-glucose and sodium L-lactate stock solutions were prepared and diluted with the respective buffers to a concentration range between $1 \mu \mathrm{mol} \mathrm{L}{ }^{-1}$ and $10 \mathrm{mmol} \mathrm{L}^{-1}$. D-Glucose solutions were allowed to mutarotate overnight. Lactate solutions in concentrations ranging between $10 \mu \mathrm{mol} \mathrm{L}{ }^{-1}$ and $10 \mathrm{mmol} \mathrm{L}^{-1}$ were additionally prepared in synthetic sweat and artificial tear fluid. Lyophilized enzymes were dissolved in PBS. The activity of the solution of glucose oxidases was $4 \mathrm{U}_{\mu} \mathrm{L}^{-1}$. For lactate oxidase, an activity of

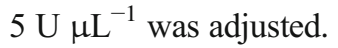




\section{Laser-scribing process and general electrode treatment}

The desired electrode structures were drawn in original size with the vector graphic software CorelDRAW 17 (Corel Corporation, Ottawa, Ontario, Canada). The CorelDRAW data are compatible with the software of the used laser-engraving device VLS 2.30 (Universal Laser Systems Inc., Scottsdale, Arizona, USA) and needs no further conversion. The electrodes were fabricated on a $125-\mu \mathrm{m}$-thick polyimide film. The scribing was performed by exposing the film to a $30 \mathrm{~W}$ $\mathrm{CO}_{2}$ laser with $1 \%$ laser power and $10 \%$ scribing speed (maximum speed is $0.127 \mathrm{~m} \mathrm{~s}^{-1}$ ). The image density parameter was set to level 7, representing 1000 laser pulses per inch (PPI) in $\mathrm{x}$-direction and 2000 PPI in y-direction. Figure S1 in the Electronic Supplementary Material (ESM) shows the schematic procedure of the laser-scribing process. Further optimizations of the scribing process are explained in the ESM. The electrodes were cleaned with water and isopropyl alcohol and dried with compressed air to remove dust traces around the pattern. The strands were isolated with two layers of nail polish. Connection pads were protected with copper tape or silver paint.

\section{Characterization of electrode material}

Morphology and graphene-like characteristics of the LIG were determined by SEM and Raman spectroscopy (see ESM, Fig. S23). Morphology was studied by SEM at $5.0 \mathrm{kV}$. The samples have been cut with a scissor and gold sputtered for $30 \mathrm{~s}(\approx 7 \mathrm{~nm}$ layer thickness) after placing them on specimen stubs. Raman spectra from 50 to $3500 \mathrm{~cm}^{-1}$ were collected on a Raman microscope with a 532-nm laser set to $8 \mathrm{~mW}$ power and a $50 \times$ objective with an estimated focal spot diameter of $0.7 \mu \mathrm{m}$. Sixteen scans were averaged per spot.

\section{Fabrication of the potentiometric sensor}

A simple design with two circular electrodes was used. Eight microliters of the ISE membrane cocktail was deposited onto one electrode to coat the whole electrode area. The membrane was dried overnight at ambient conditions. For RE fabrication, $20 \mu \mathrm{L}$ of $\mathrm{AgNO}_{3}$ solution $\left(\beta=400 \mathrm{mg} \cdot \mathrm{mL}^{-1}\right)$ was dropped on the RE and equilibrated on the electrode for $5 \mathrm{~min}$. A commercial handheld plating device with a voltage of $3 \mathrm{~V}$ and a current of $300 \mathrm{~mA}$ was used. The plating process was carried out for $1 \mathrm{~min}$. The electrode was immersed into a saturated $\mathrm{KCl}$ solution and a $0.8 \mathrm{~V}$ (vs. $\mathrm{Ag} / \mathrm{AgCl}$ ) $\mathrm{DC}$ voltage was applied for $200 \mathrm{~s}$ to receive the silver chloride layer on top. The entire modification process is schematically shown in Fig. S9 (see ESM). For further information regarding the optimization process, see ESM.

\section{Design of the impedance sensor}

An applicable design with interdigitated two-electrode structure was developed and optimized (see ESM). The sensor needed no further modifications.

\section{Amperometric biosensor with layered working electrode}

A three-electrode setup based on commercially available planar sensor systems was chosen. Two microliters of each iron salt precursor solution was applied exclusively onto the working electrode (WE) area and allowed to react there for $20 \mathrm{~min}$ under ambient conditions. The formed PB layer is stabilized for $2 \mathrm{~h}$ at $100{ }^{\circ} \mathrm{C}$. The chitosan membrane was applied by drop-coating $2 \mu \mathrm{L}$ of the chitosan solution on the PBmodified WE. The membrane was dried for 90 min under ambient conditions. Two microliters of the respective enzyme solution was applied to the dried chitosan membrane. For incubation, the electrodes were stored at least $2 \mathrm{~h}$ at ambient conditions, or overnight at $4{ }^{\circ} \mathrm{C}$. A scheme of the entire buildup of the modified WE is shown in Fig. 1. Reference electrode (RE) and counter electrode (CE) were made from unmodified LIG. After cleaning with a few droplets of buffer solution, the sensors were ready to use.

\section{Multi-analyte design}

The three single-analyte sensor designs were combined so that the amperometric and potentiometric sensors share a circular $\mathrm{RE}$ with electrodeposited $\mathrm{Ag} / \mathrm{AgCl}$ layer like shown in Fig. 2c.

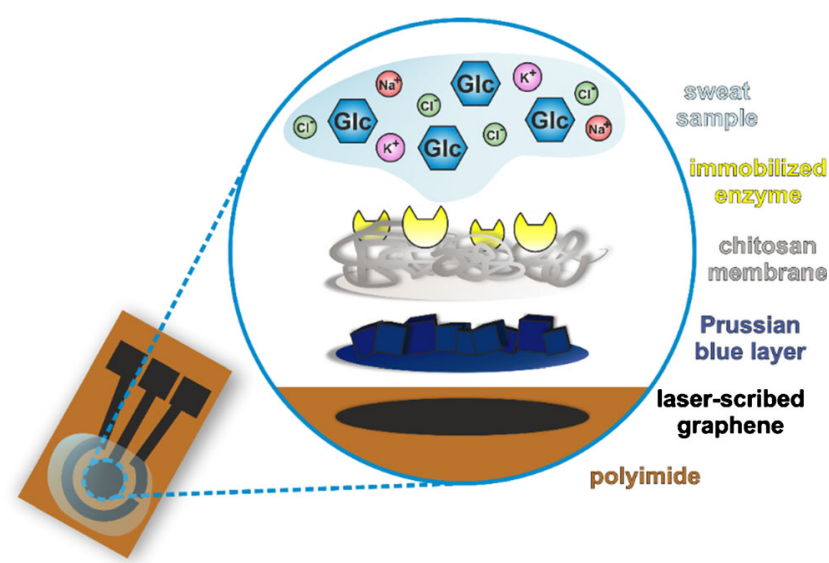

Fig. 1 Scheme of the WE of the amperometric biosensor after all modification steps. The laser-induced graphene on the flexible PI substrate is the base for the chemical deposited PB layer. The chitosan membrane fixes the PB layer while providing the polymer network on which the enzyme is immobilized. The sweat sample or any other solution is applied on top 
a

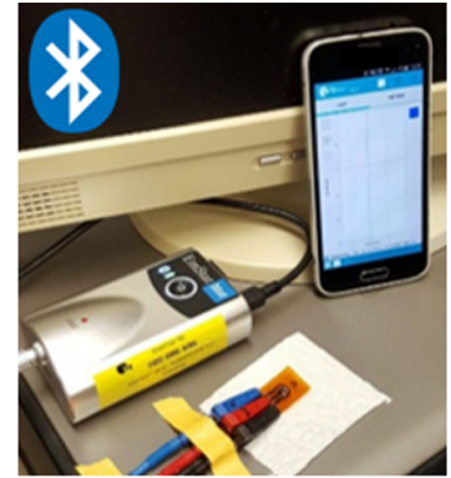

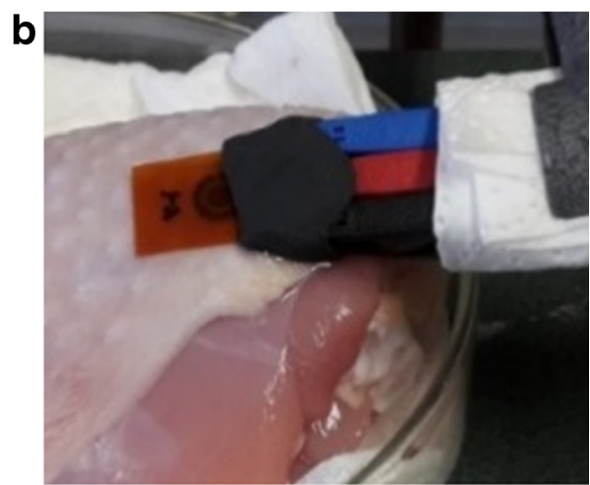

C

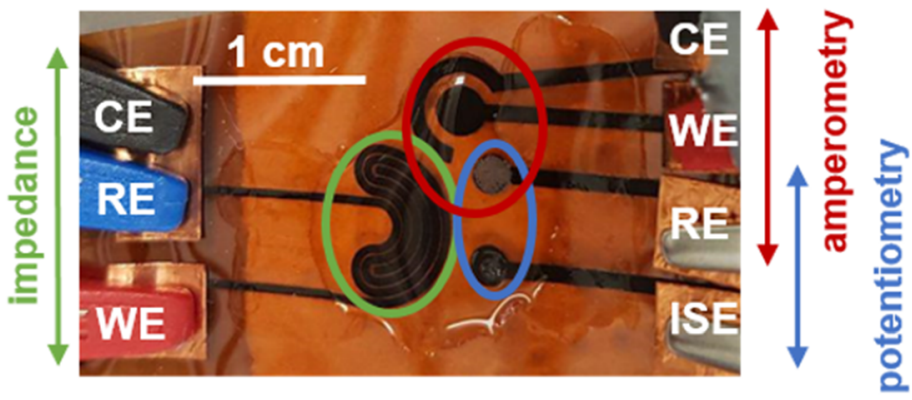

d

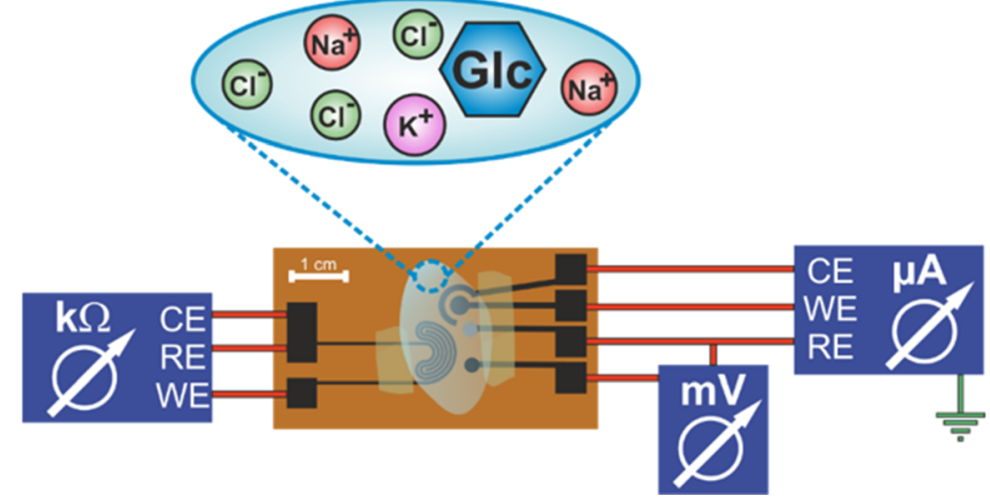

Fig. 2 a Sensor connected to the EmStat Blue potentiostat via three crocodile clamps attached to the connection pads. For planar setup, a sample droplet of $30 \mu \mathrm{L}$ which covers all three electrodes was added. There is a wireless connection of the potentiostat via Bluetooth $₫$ to the software application installed on a smartphone. b Experimental setup for detection of glucose and lactate with amperometric measurements on a chicken leg to simulate human skin and to provide a biological substrate. A piece of filter paper is used as simulated sweat collection pad. Modeling clay protects the contacts from moisture due to the shortened strands. The sensor is in a fixed position, whereas the chicken substrate

\section{General procedures and instrumental settings}

For potentiometric measurements, both electrodes were connected to a multimeter, $30 \mu \mathrm{L}$ of sample solution was applied, and the potential was read off immediately. The sensor was carefully swabbed with tissue and the next solution was applied. The same procedure was performed with all other sample solutions. Sample application without using sweat collection pads is herein called droplet method. In case of using filter paper or gauze as sample collection pad, sample volume was doubled. with the applied sample can be moved up and down. c Combined LIG sensor. Connection pads are protected with adhesive copper tape against abrasion through the crocodile clamps. The strands are isolated by nail polish. $150 \mu \mathrm{L}$ to $200 \mu \mathrm{L}$ of sample solution is suitable to cover the active electrode area. d Schematic view of the combined LIG biosensor on polyimide substrate connected to two potentiostats and a multimeter. $150 \mu \mathrm{L}$ to $200 \mu \mathrm{L}$ of mixed samples containing all potential analytes is applied and can be measured quasi simultaneously after calibration of the single sensors

For impedance measurements, $100 \mu \mathrm{L}$ of the respective ion solution was applied and the measurement was started at a fixed frequency of $1000 \mathrm{~Hz}$ with an $\mathrm{AC}$ amplitude of $10 \mathrm{mV}$ and $\mathrm{DC}$ potential of $0 \mathrm{~V}$, immediately. After the measurement was finished, the solution was carefully swabbed away with a paper towel and the respective following solution with increasing analyte concentration was applied.

The amperometric sensor was connected to a commercial software-controlled potentiostat. For the general procedure, a droplet of $30 \mu \mathrm{L}$ of the respective sample 
solution was applied to the biosensor (with and without filter paper as sweat collection substrate) and the measurement was started immediately. Different experimental setups are shown in Fig. $2 \mathrm{a}$ and $\mathrm{b}$. The working range of the sensors was determined by measuring a cyclic voltammogram (CV) of PBS between $0.85 \mathrm{~V}$ and $-0.95 \mathrm{~V}$ vs. LIG with a scan speed of $50 \mathrm{mV} \mathrm{s}^{-1}$. The $\mathrm{CVs}$ showed usually four characteristic peaks of the respective reduction and oxidation steps of the PB mediator layer. A potential in the decay of the first oxidation peak, usually between $-0.1 \mathrm{~V}$ and $0.1 \mathrm{~V}$ vs. LIG, was chosen for the amperometric determinations. If the $\mathrm{Ag} / \mathrm{AgCl} \mathrm{RE}$ was used, the $\mathrm{CV}$ settings were adjusted to a slightly higher potential. With the same experimental setup, the chronoamperometric measurements were performed with a run time of $60 \mathrm{~s}$ and the potential determined from the $\mathrm{CV}$. To equilibrate the sensor, buffer was measured for at least five times. The measurement was started immediately after sample application without further incubation time. The droplet on the electrode was carefully absorbed with a paper towel and the next sample solution was applied.

For the multi-analyte sensor, $150 \mu \mathrm{L}$ of sample solution containing different amounts of each analyte was applied to the multi-electrode system. For a quasisimultaneous acquisition, the potential difference of the ISE was read out first after sample application. Then, the impedance was measured and as last step, the amperometric detection was done. In summary, one analytical cycle takes approximately $75 \mathrm{~s}$. A schematic experimental setup is shown in Fig. 2c and d.

Some measurements were performed with filter paper or gauze as sweat collection pad and on a chicken leg with skin to simulate detection under more real conditions (see Fig. $2 b$ for the experimental setup). Moreover, lactate quantification was performed in synthetic sweat solution according to DIN 53160-2 and in artificial tear fluid.

\section{Statistics and data evaluation}

All calculations, especially the arithmetic mean values and standard deviation (SD), were calculated with Microsoft Excel 2016 (Microsoft Corporation, Redmond, Washington, USA). Usually, measurements were performed at least in triplicate $(n=3)$. Suspicious values were removed after failing the outlier Q-test. SD is represented by error bars in y-direction.

Linear and non-linear regression curves were accomplished with following Eqs. (1) and (2). Lower limit of detection (LOD) and lower limit of quantification (LOQ) for linear calibration curves were calculated with Eqs. (3) and (4). To calculate the LOD and LOQ from a sigmoidal fit curve, the Eqs. (5) and (6) were used.

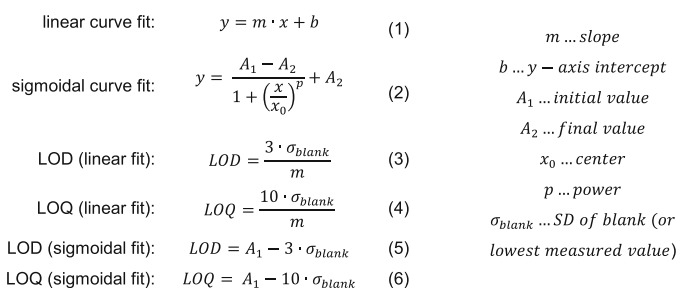

\section{Results and discussion}

The development strategy of the multi-analyte all-LIG sensor is based on an initial study of each single sensing principle separately. Electrode layout, laser-scribing conditions, and all other depending parameters and procedures were optimized to serve all three sensing concepts well. The key was to demonstrate that an all-LIG concept is possible for all three electroanalytical detection strategies and that those can easily be combined for multi-analyte detection.

\section{Potentiometric sensor for potassium ion quantification}

The LIG-based sensor for potentiometric determination of potassium ions consists of an ion-selective electrode with valinomycin embedding PVC membrane and an electrodeposited $\mathrm{Ag} / \mathrm{AgCl}$ reference electrode. The potential of the reference electrode fabricated via galvanic silver plating and subsequent electrochemical oxidation in saturated $\mathrm{KCl}$ solution was measured vs. a silver chloride-coated silver wire. A difference below $1 \mathrm{mV}$ indicated a well-working production process. A planar design with circular electrodes was chosen considering a future application as sweat sensor worn on skin. Size, distance, and shape of the electrodes were optimized for best performance (see ESM, Figs. S3-S9) resulting in a wellworking all-LIG sensor with relative errors below $4 \%$ (Fig. 3). Specifically, $\mathrm{K}^{+}$detection worked within a concentration range of $1 \cdot 10^{-5} \mathrm{~mol} \mathrm{~L}^{-1}$ to $1 \mathrm{~mol} \mathrm{~L}^{-1} \mathrm{KCl}$ when covering the electrodes with a single droplet of sample solution. Using filter paper as simulated sweat collection pad, the lower linear range limit increased to $1 \mathrm{mmol} \mathrm{L}^{-1} \mathrm{KCl}$ indicating an expected direct negative impact on the ion diffusion profile to the sensor surface. As the median range of interest for $\mathrm{K}^{+}$ analysis in sweat is fluctuating around $5 \mathrm{mmol} \mathrm{L}^{-1}$ with peak values up to $38 \mathrm{mmol} \mathrm{L}^{-1}[5,29,30]$, the dynamic range of the sensor is an excellent fit. Furthermore, due to valinomycin, a good selectivity towards $\mathrm{K}^{+}$ions was demonstrated compared with the main interfering cations $\mathrm{Na}^{+}, \mathrm{Mg}^{2+}$, and $\mathrm{Ca}^{2+}$ as shown in Fig. S5 (see ESM).

As can be seen in Fig. 3a and b, the slopes of the doseresponse curves are around $95 \mathrm{mV} \cdot \mathrm{dec}^{-1}$ in case of using the electrodeposited $\mathrm{Ag} / \mathrm{AgCl} \mathrm{RE}$. This indicates that our pseudo $\mathrm{Ag} / \mathrm{AgCl}$ reference electrode contributes to the signal and 

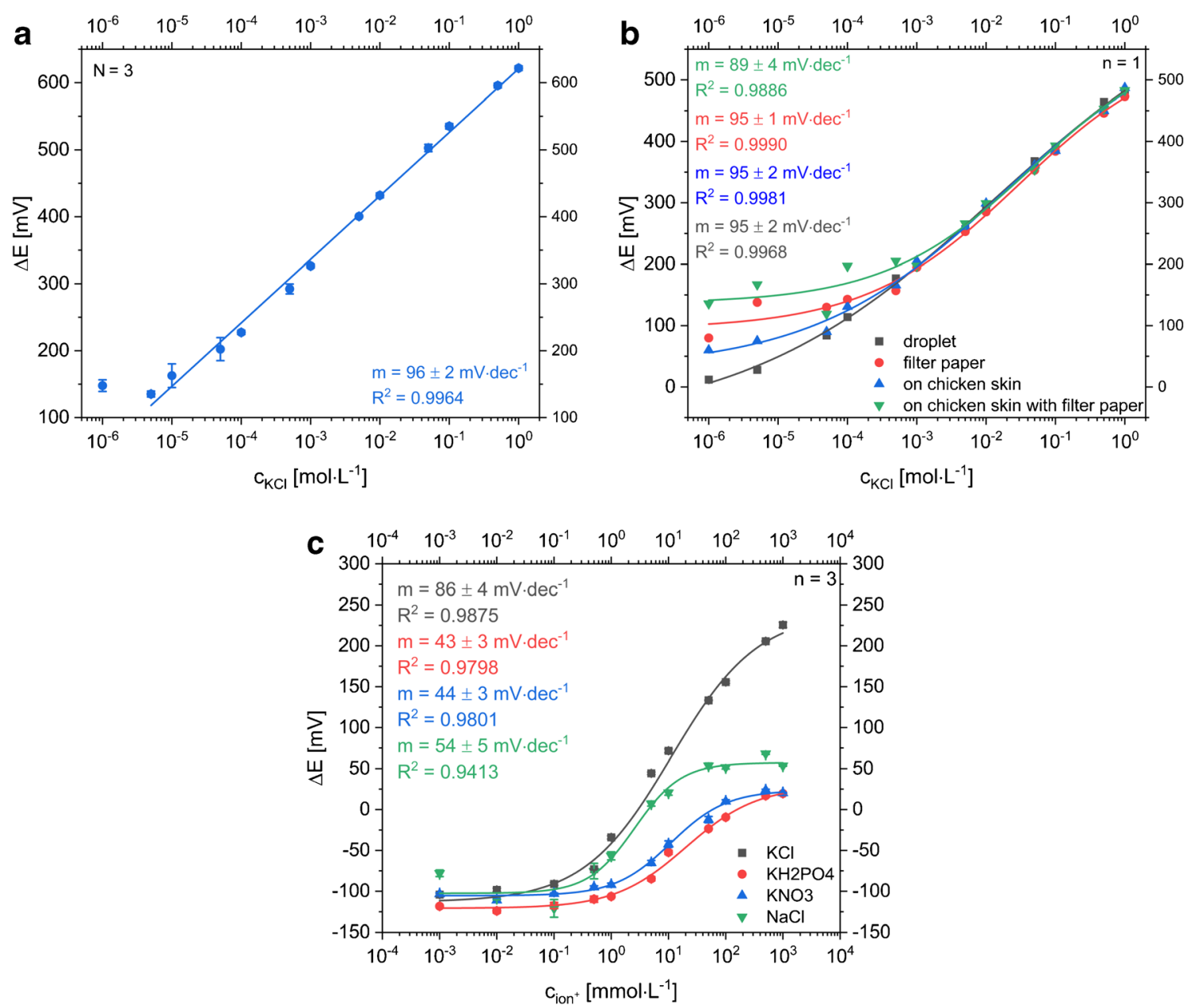

Fig. 3 a Dose-response curve of a potentiometric, planar LIG-based sensor with $\mathrm{Ag} / \mathrm{AgCl} \mathrm{RE}$ measuring $\mathrm{KCl}$ concentrations ranging from $10^{-6}$ to $1 \mathrm{~mol} \mathrm{~L}^{-1}$ with the droplet method $\left(\mathrm{N}_{\text {sensor }}=3\right)$. The linear range goes down to $1 \cdot 10^{-5} \mathrm{~mol} \mathrm{~L}{ }^{-1} \mathrm{KCl}$ and the slope is $96 \pm 2 \mathrm{mV} \cdot \mathrm{dec}^{-1}$. The small standard deviation, represented as error bars, especially in the linear range, indicates a reproducible electrode fabrication procedure. b Doseresponse curves of the potentiometric LIG sensor with $\mathrm{Ag} / \mathrm{AgCl} \mathrm{RE} . \mathrm{KCl}$

responds to the chloride ions of the $\mathrm{KCl}$ standards accordingly. This was demonstrated by simply performing the same experiments with $\mathrm{KNO}_{3}, \mathrm{NaCl}$, and $\mathrm{KH}_{2} \mathrm{PO}_{4}$ (Fig. 3c), whereas the other electrolytes showed just half of the slope in contrast to the dose-response curve for $\mathrm{KCl}$.

In theory, a $118 \mathrm{mV}$ slope (i.e., $2 \times$ Nernstian slope of $59 \mathrm{mV}$ ) would be expected for $\mathrm{KCl}$ additions. However, the pre-deposition of $\mathrm{AgCl}$ on the pseudo reference electrode likely prevents that. For actual $\mathrm{K}^{+}$ion quantification in sweat, two strategies can be used. Either a simple LIG electrode can be applied as reference material or the pseudo- $\mathrm{RE}$ will be covered with a Nafion/KCl/PVC membrane (Fig. 4). The additional membrane keeps chloride concentration at the RE constant and prevents $\mathrm{Cl}^{-}$ions from the sample to interfere. Besides the reduced sensitivity caused by the increased resistance, both strategies show a suitable way to minimize the influence of chloride ions within the relevant range. Moreover, we samples were measured by application of droplets (gray boxes), using a filter paper as sweat collection pad (red circles), measuring sample droplets on chicken skin (blue triangle) and on chicken skin with filter paper (green triangle). c Dose-response curves of one sensor when different electrolytes containing $\mathrm{K}^{+}$and $\mathrm{Cl}^{-}$ions are measured to demonstrate the sensor's sensitivity towards both species (gray boxes: $\mathrm{KCl}$, red circles $\mathrm{KH}_{2} \mathrm{PO}_{4}$, blue triangles: $\mathrm{KNO}_{3}$ green triangles: $\mathrm{NaCl}$ )

expect that the unprotected $\mathrm{Ag} / \mathrm{AgCl}$ electrode in combination with another RE works as simple chloride ion sensor.

It should be pointed out that the overall fabrication of the potentiometric sensors is reliable even on lab-scale as shown by minimal differences in slopes and low standard deviations (Figs. 3, 4, and 8). However, it can also be seen that each change in sensor setup creates additional resistance layers which is reflected in the varying slopes observed in these data sets, i.e., sensors without Nafion layer follow a Nernstian behavior, as those with additional PVC and Nafion layers, or when mechanically disturbed by filter paper or gauzes show an overall decrease in slope.

\section{Impedance sensor for electrolyte quantification}

EIS was used to quantify the overall electrolyte content in sweat. Electrolyte concentration in sweat is an important 


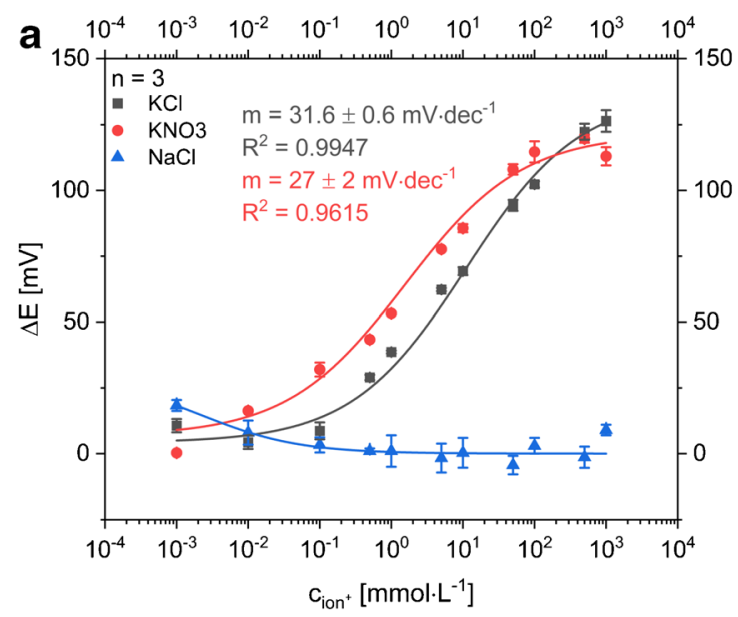

Fig. 4 Dose-response curves of all-LIG potentiometric sensors with an ISE versus different $\mathrm{RE}$ a $\mathrm{Ag} / \mathrm{AgCl}$ pseudo- $\mathrm{RE}$ was protected by a $\mathrm{Nafion} / \mathrm{KCl} / \mathrm{PVC}$ layer and $\mathbf{b}$ an unmodified LIG was used as RE material

indicator for the hydration level of the body. Therefore, an interdigitated LIG electrode structure was designed and optimized (see ESM, Fig. S10-S15). The impedance measurement with the kidney-shaped sensor was performed at constant frequency of $1 \mathrm{kHz}$ with a fixed amplitude of $10 \mathrm{mV}$ to enable a fast response of the sensor. Application of $\mathrm{KCl}$ solutions to the sensor with and without filter paper as sweat collection pad showed small standard deviations and similar curve shapes in the physiological-relevant electrolyte concentration range of $1 \mathrm{mmol} \mathrm{L}^{-1}$ to $1 \mathrm{~mol} \mathrm{~L}^{-1}$ [5] (see Fig. 5). Ion concentrations in sweat range from lower millimolar

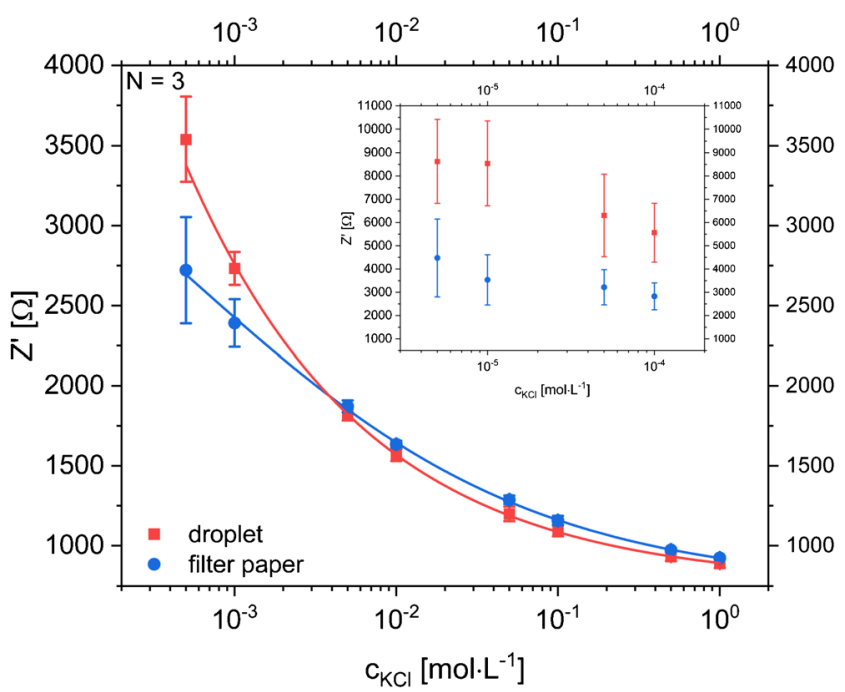

Fig. 5 Dose-response curve of impedance measurements of $\mathrm{KCl}$ solutions with concentrations ranging between $5 \cdot 10^{-4}$ and $1 \mathrm{~mol} \mathrm{~L}^{-1}$ in a planar all-LIG setup $\left(\mathrm{N}_{\text {sensor }}=3\right)$ with the droplet method (blue circles) and Whatman ${ }^{\circledR} 595$ filter paper (red boxes) to simulate a sweat collection pad. The inset shows a zoomed-in section for the concentration range below the relevant range. Instrumental settings: fixed frequency of $1000 \mathrm{~Hz}$ with an AC amplitude of $10 \mathrm{mV}$ and DC potential of $0 \mathrm{~V}$

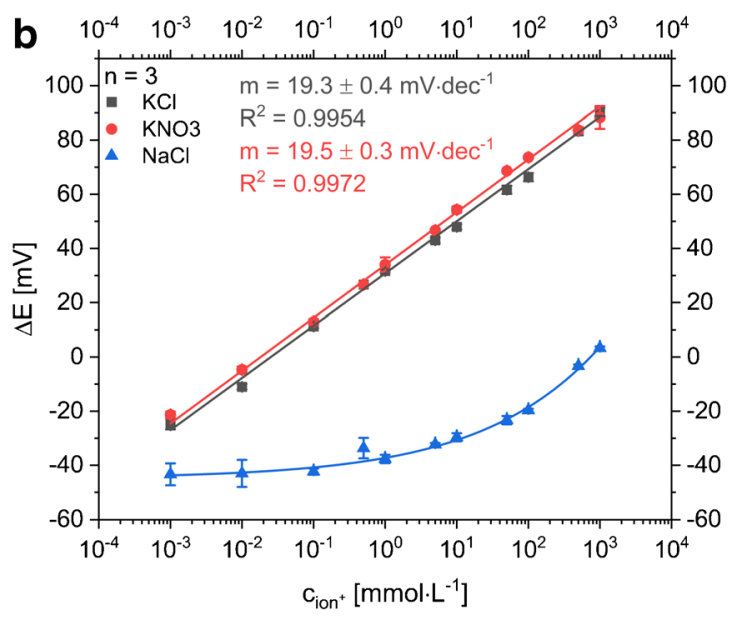

to minimize the influence of chloride ions (gray boxes: $\mathrm{KCl}$, red circles $\mathrm{KNO}_{3}$, blue triangles: $\mathrm{NaCl} ; n=3$ )

concentrations up to peak values over $0.5 \mathrm{~mol} \mathrm{~L}^{-1}$ which is well within the reliable detection range of this sensor $[5,12]$.

\section{Amperometric glucose and lactate biosensors}

Enzyme-based biosensors were developed for the amperometric detection of glucose and lactate. Glucose oxidase and lactate oxidase were used as their reaction with the respective analytes produce $\mathrm{H}_{2} \mathrm{O}_{2}$, which can easily be detected on Prussian bluecoated carbon electrodes. Chitosan membranes were selected as protection membranes and scaffolds for enzyme immobilization due to their wide-spread and established performance in such enzyme sensors [1, 2, 31-37]. Here, these wellestablished concepts were established on the LIG electrodes. Enzyme immobilization, Prussian blue coating, chitosan membrane protection as well as acquisition and incubation time were optimized (see ESM Figs. S16-S20). For most of the optimizations steps, hydrogen peroxide (HP) sensors (without immobilized enzyme) were used and the characteristics of the underlying $\mathrm{H}_{2} \mathrm{O}_{2}$ sensor are shown in Table 1. Subsequently, the glucose sensor was tested in solution by dropping sample volumes onto the electrodes (Fig. 6), with a simulated sweat collection pad (wipe) and on chicken skin (Table 1). In the case of the droplet method, a limit of detection (LOD) of $13.7 \pm$ $0.5 \mu \mathrm{mol} \mathrm{L}^{-1}$ and a limit of quantification (LOQ) of $42 \pm$ $2 \mu \mathrm{mol} \mathrm{L}{ }^{-1}$ were calculated from dose-response curves with an upper limit of the dynamic range around $2 \mathrm{mmol} \mathrm{L}^{-1}$ and a sensitivity of $20.0 \pm 0.8 \mu \mathrm{A} \mathrm{L} \mathrm{mmol}^{-1} \mathrm{~cm}^{-2}$. For the application intended, the detectable concentration range is appropriate, as glucose concentrations in sweat are in the range between $6 \mu \mathrm{mol} \mathrm{L} \mathrm{L}^{-1}$ and $2.2 \mathrm{mmol} \mathrm{L}^{-1}$ with a median value of $170 \mu \mathrm{mol} \mathrm{L}^{-1}$ reported [5].

In the case of filter paper and chicken skin analyses, LOD and LOQ are increased by a factor of nine to $120 \pm 4 \mu \mathrm{mol} \mathrm{L}{ }^{-1}$ and $365 \pm 11 \mu \mathrm{mol} \mathrm{L}{ }^{-1}$, respectively. The sensitivity of the 
Table 1 Comparison of important sensor characteristics determined with droplet method and sweat-collecting substrate for chronoamperometric detection of the respective analytes hydrogen peroxide, glucose, and lactate in $1 \times$ PBS pH 7.4 as well as in synthetic sweat solution according to DIN 53160-2 and artificial tear fluid with droplet application

\begin{tabular}{|c|c|c|c|c|c|c|c|}
\hline \multirow{2}{*}{$\begin{array}{l}\text { Analyte } \\
\text { Sample application via }\end{array}$} & \multirow{2}{*}{$\begin{array}{l}\mathrm{H}_{2} \mathrm{O}_{2} \\
\text { Droplet }\end{array}$} & \multicolumn{2}{|l|}{ Glucose } & \multicolumn{4}{|l|}{ Lactate } \\
\hline & & Droplet & Filter on skin & Droplet & $\begin{array}{l}\text { Synthetic sweat } \\
\text { solution droplet }\end{array}$ & $\begin{array}{l}\text { Artificial tear } \\
\text { fluid droplet }\end{array}$ & Gauze \\
\hline $\operatorname{LOD}\left(\mu \mathrm{mol} \mathrm{L}{ }^{-1}\right)$ & $121 \pm 6$ & $13.7 \pm 0.5$ & $120 \pm 4$ & $28 \pm 3$ & $25 \pm 4$ & $82 \pm 1$ & $133 \pm 1$ \\
\hline $\operatorname{LOQ}\left(\mu \mathrm{mol} \cdot \mathrm{L}^{-\mathbf{1}}\right)$ & $367 \pm 2$ & $42 \pm 2$ & $365 \pm 11$ & $86 \pm 6$ & $76 \pm 11$ & $249 \pm 2$ & $415 \pm 3$ \\
\hline Linear range up to $\left(\mathrm{mmol} \mathrm{L}^{-\mathbf{1}}\right)$ & 5 & 1.5 & 1.5 & 1 & 5 & 1 & 2.5 \\
\hline Sensitivity $\left(\mu \mathrm{A} \mathrm{L} \mathrm{mmol}{ }^{-1} \mathrm{~cm}^{-2}\right)$ & $3.0 \pm 0.1$ & $20.0 \pm 0.8$ & $4.5 \pm 0.1$ & $16 \pm 1$ & $6.1 \pm 0.4$ & $4.5 \pm 0.6$ & $1.75 \pm 0.01$ \\
\hline $\operatorname{adj} . R^{2}$ & 0.9736 & 0.9860 & 0.9895 & 0.9633 & 0.9377 & 0.9989 & 0.9864 \\
\hline
\end{tabular}

sensor decreased by a factor of five to $4.5 \pm$ $0.1 \mu \mathrm{A} \mathrm{L} \mathrm{mmol}{ }^{-1} \mathrm{~cm}^{-2}$ (ESM Fig. S21 b). We therefore suggest to change the sweat collection to other strategies in the future, such as macro-collection channels as published by Lei et al. [38], as also indicated by further CV analyses (ESM Fig. S21 a). This strategy would provide better analyte diffusion profiles and hence create conditions similar to those established in the droplet method.

Due to the broad $\mathrm{pH}$ range of sweat based on different factors like collection point, extent of activity, or fitness level of the individuals $[6,39]$, dose-response curves for glucose were recorded between $\mathrm{pH} 4$ and $\mathrm{pH} 7$. Each curve was measured on one sensor with an applied potential of $0 \mathrm{~V}$ vs LIG. The resulting dose-response curves and the calculated sensor specifications are comparable (Fig. 7). The dose-response curves were normalized due to the varying sensitivities of the different sensors. If the manual modification steps are replaced by an automated method, we assume that the reproducibility of the sensitivity can be increased. Currently, a two-

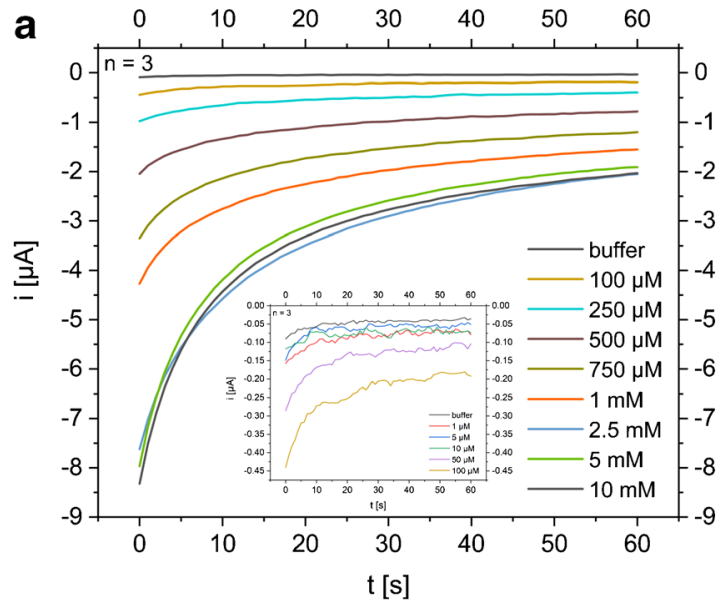

Fig. 6 a Exemplary time versus current curves of chronoamperometric characterization of a modified glucose biosensor with chemical deposited Prussian blue layer, $0.1 \%$ chitosan membrane, and theoretical GOx activity of $1 \mathrm{U} \mathrm{mm}^{-2}(n=3$, error bars are hidden for clarity). The applied potential was $-50 \mathrm{mV}$ vs. LIG. Run time was $60 \mathrm{~s}$ and the sample was applied as a droplet. The magnified cutout demonstrates point calibration for the lowest and highest concentration and normalization is a satisfying procedure for comparison.

Upon simply exchanging the enzyme from glucose to lactate oxidase, the strength of the sensor concept became obvious. No further optimization experiments were required. The lactate detection in the droplet format was performed within a concentration range from $10 \mu \mathrm{mol} \mathrm{L}^{-1}$ to $5 \mathrm{mmol} \mathrm{L}^{-1}$. A LOD of $28 \pm 3 \mu \mathrm{mol} \mathrm{L}{ }^{-1}$ and a LOQ of $86 \pm 8 \mu \mathrm{mol} \mathrm{L}{ }^{-1}$ were obtained with a sensitivity of $16 \pm 1 \mu \mathrm{A} \mathrm{L} \mathrm{mmol}{ }^{-1} \mathrm{~cm}^{-2}$ (Table 1). Interestingly, the sensor is too sensitive for lactate concentrations in sweat, which ranges from 3.7 up to $50 \mathrm{mmol} \mathrm{L}^{-1}[5,40]$. This high level is a well-known challenge for oxidase-based biosensors in literature [5, 29, 41]. To overcome this challenge, perforated membranes could be used as demonstrated previously by our groups [38]. Experiments with gauze for sweat collection showed the same trend as previously seen for glucose detection. LOD and LOQ declined nearly by a factor of five compared with the droplet

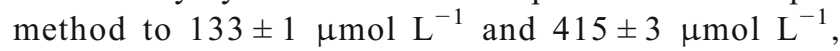

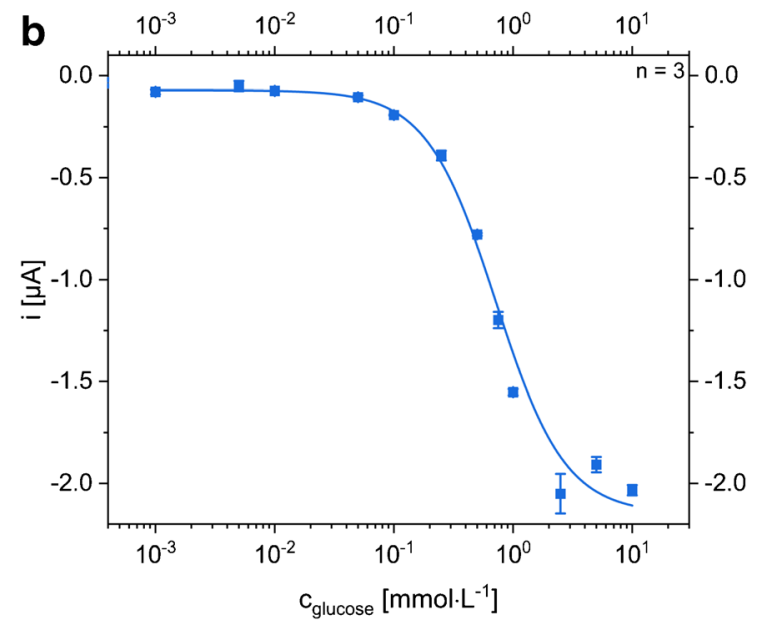

that low glucose solutions can be distinguished from each other. b Dose-response curve ( $n=3$, SD represented by error bars, droplet method) resulting from the respective I vs. $t$ curve after a run time of $60 \mathrm{~s}$ on half-logarithmic scale. LOD is $13.7 \pm 0.5 \mu \mathrm{mol} \mathrm{L}^{-1}$ and LOQ is $42 \pm$ $2 \mu \mathrm{mol} \mathrm{L}{ }^{-1}$ 
Fig. 7 a Normalized doseresponse curves of glucose in phosphate/citrate buffers at different physiological-relevant $\mathrm{pH}$ values (between 4 and 7). For each $\mathrm{pH}$ value, a new sensor was taken. A potential of $\mathrm{E}=0 \mathrm{~V}$ vs. LIG was applied for all chronoamperometric measurements. All curves have a highly comparable shape independent of $\mathrm{pH}$. Normalization of the signals from different sensors is necessary due to the varying sensitivity of the manually fabricated sensors. b Summary of important characteristics for the glucose sensors at different physiologicalrelevant $\mathrm{pH}$ ranges

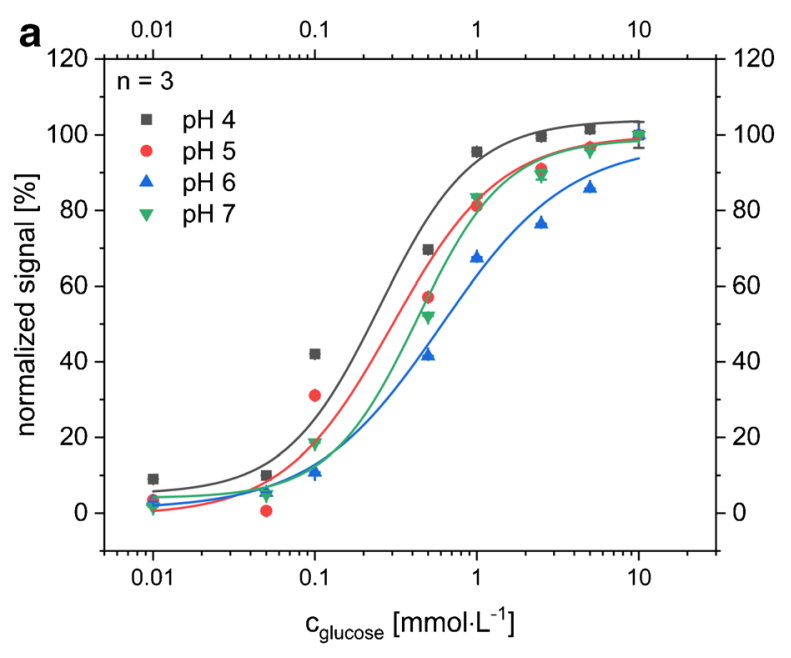

b

\begin{tabular}{|c|c|c|c|c|}
\hline & $\mathrm{pH} 4$ & $\mathrm{pH} 5$ & pH 6 & pH 7 \\
\hline $\begin{array}{c}\text { LOD } \\
{\left[\mu \mathrm{mol} \cdot \mathrm{L}^{-1}\right]}\end{array}$ & $71 \pm 2$ & $42 \pm 6$ & $77 \pm 6$ & $75 \pm 5$ \\
\hline $\begin{array}{c}\text { LOQ } \\
{\left[\mu \mathrm{mol} \cdot \mathrm{L}^{-1}\right]}\end{array}$ & $215 \pm 5$ & $127 \pm 18$ & $280 \pm 21$ & $229 \pm 16$ \\
\hline $\begin{array}{l}\text { linear range up to } \\
{\left[\mathrm{mmol} \cdot \mathrm{L}^{-1}\right]}\end{array}$ & 2.5 & 2.5 & 2.5 & 2.5 \\
\hline $\begin{array}{c}\text { Sensitivity } \\
{\left[\mu \mathrm{A} \cdot \mathrm{L} \cdot \mathrm{mmol} \mathbf{l}^{-1} \cdot \mathrm{cm}^{-2}\right]}\end{array}$ & $6.1 \pm 0.1$ & $2.0 \pm 0.3$ & $0.85 \pm 0.04$ & $2.0 \pm 0.1$ \\
\hline$R^{2}$ & 0.9972 & 0.9982 & 0.9983 & 0.9976 \\
\hline
\end{tabular}

respectively, with a sensitivity of $1.75 \pm$ $0.01 \mu \mathrm{A} \mathrm{L} \mathrm{mmol}{ }^{-1} \mathrm{~cm}^{-2}$. In the case of lactate, the LIGlactate sensor performs well within the lower physiologicalrelevant range. At the same time, materials other than gauze should be investigated in the future such as specialized polymer sponges, hydrophobic fibers, or microfluidic channels [41-46].

In the case of lactate as analyte, measurements in synthetic sweat matrix (DIN 53160-2) and in artificial tear fluid were also performed using the droplet method. Data plots for lactate measurements are shown in Fig. S22 (see ESM). The values of sensitivity, LOD, and LOQ are summarized and compared with all other amperometric determinations in Table 1.

The enzymatic sensors show at least comparable or even better LOD/LOQ and sensitivity than the underlying HP sensor. As the HP is produced directly on the sensor surface in the case of the enzyme sensors, dependence on HP diffusion is minimized and therefore the sensitivity can be improved. The sensor's performances prove their applicability for the detection of glucose and lactate in the respective fluids representing real samples. While LOD and upper detection limit are shifted to higher values in comparison with their performance in buffer solution, the sensors are a suitable platform for quantification within the physiological range of lactate in eccrine sweat (3.7-50 $\mathrm{mmol} \mathrm{L}^{-1}$ [5]) and tear fluid (1 to $5 \mathrm{mmol} \mathrm{L}^{-1}$ [47]). As indicated in Table 1, various filter papers were studied to function as sweat collection material. Depending on the ability to hold aqueous solution on top of the sensor surface, more or less hindrance of the detection itself was observed. Materials similar to simple filter paper work well in most instances as indicated by the filter paper, Kimwipe tissue, and gauze data shown. Moreover, all favorable data obtained from the singleparameter sensors suggested combining the sensors to a miniaturized POC multi-analyte sensing platform for a reliable and affordable sweat analysis.

\section{Combined multi-analyte sensor}

For the multi-analyte concept, the first challenge was to minimize the sensor area to provide reliable responses with analyte volumes as low as possible. Therefore, the $\mathrm{Ag} / \mathrm{AgCl}$ reference electrode is successfully shared by the potentiometric and the amperometric setup (Fig. $2 \mathrm{c}$ and d). Cross talk of the electrodes is minimized by choosing a semi-simultaneous measurement approach in which sensors are turned on and off consecutively within a short time. Each analytical cycle (potentiometry, impedance, and chronoamperometry) requires only $75 \mathrm{~s}$, and hence allows a quasi-continuous and simultaneous monitoring of all analytes. In this format, dynamic ranges and LOD/LOQ are comparable with the characteristics obtained for the single-parameter sensors (Fig. 8). This indicates that the changed layout and electrode geometry 

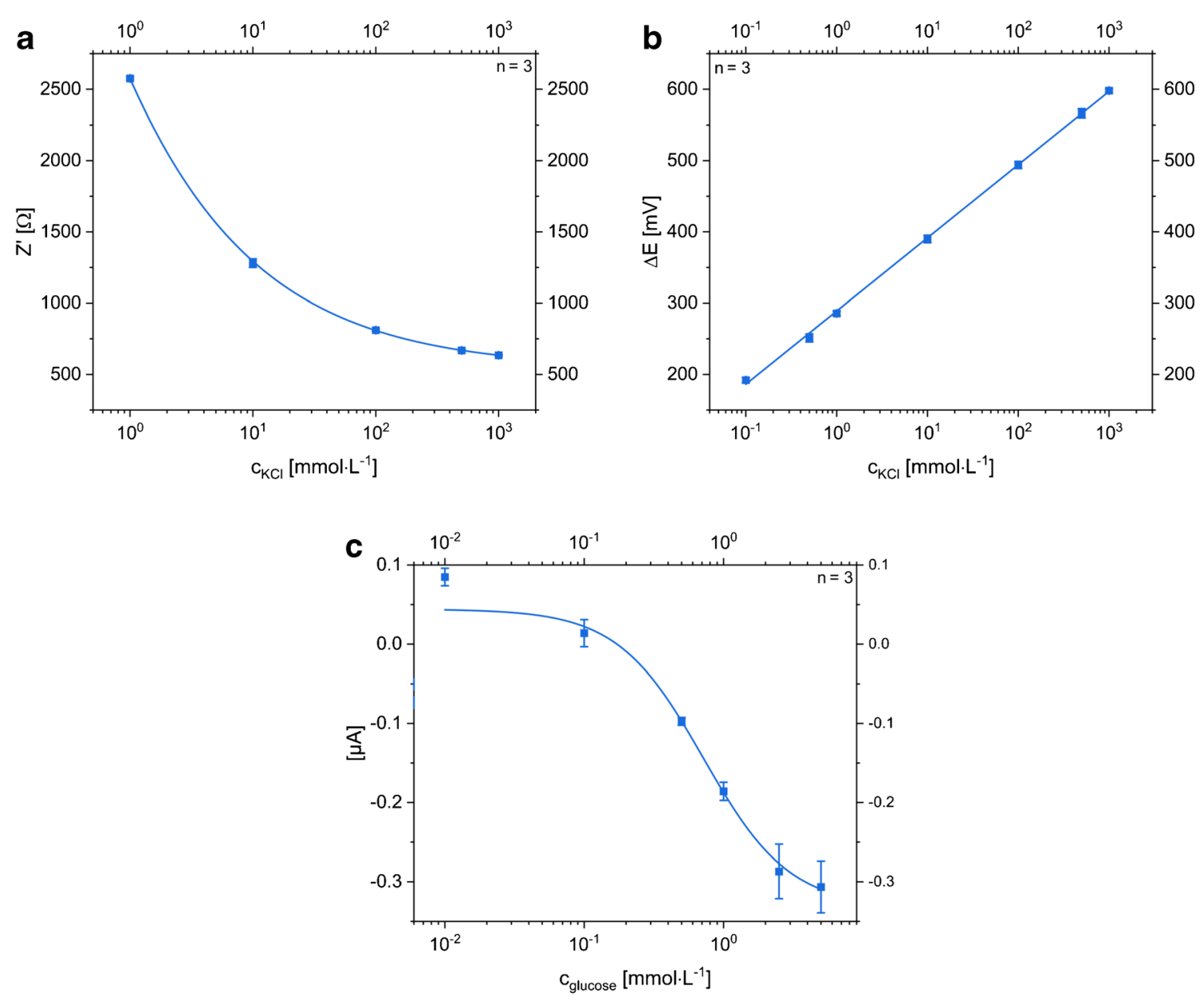

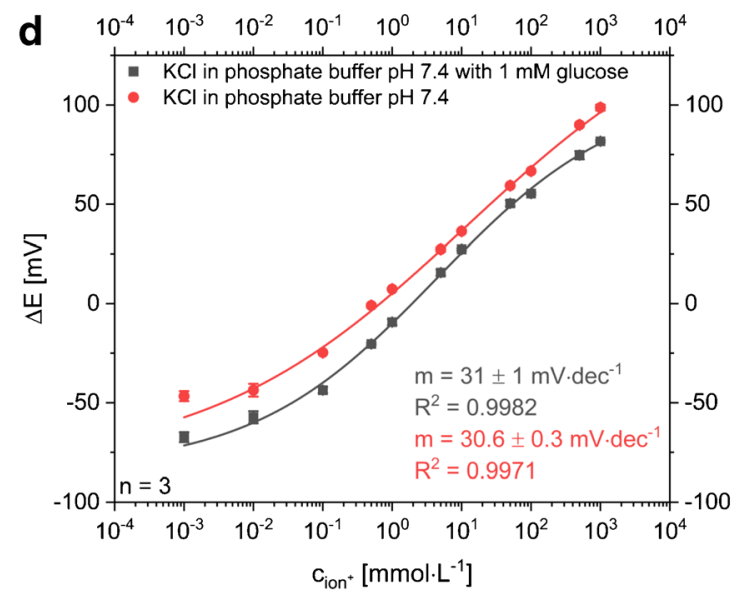

Fig. 8 Dose-response curves of combined multi-analyte sensor for three determination methods under the same conditions as for the singleanalyte sensor. All techniques show a comparable response as the single-analyte sensors. a The all-electrolyte concentration with the impedance measurement is highly reliable in the physiological-relevant range from 1 to $500 \mathrm{mmol} \mathrm{L}^{-1}$. b A similar reliability within the relevant

do not affect the performance. Most interestingly, it proves that multi-analyte sensing in an all-LIG format using any of the desirable electrochemical techniques can be realized and

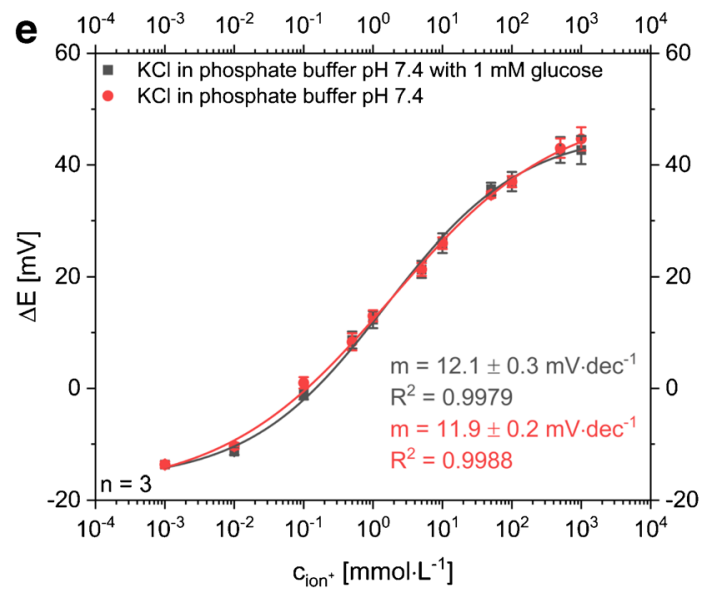

range is provided for the detection of potassium concentrations with the potentiometric sensor. The slope of the linear fit is $103 \pm 1 \mathrm{mmol} \mathrm{dec}^{-1}$. Glucose determination with the amperometric setup. LOD of $135 \pm$ $5 \mu \mathrm{mol} \mathrm{L}{ }^{-1}$ and LOQ of $410 \pm 15 \mu \mathrm{mol} \mathrm{L} \mathrm{L}^{-1}$ were obtained. Potentiometric determinations were performed with a $\mathbf{d} \mathrm{Nafion} / \mathrm{KCl} /$ PVC-protected RE and a e LIG RE

easily adapted to other analytes of interest to which ionophores or enzymes are available. 
Table 2 Overview of comparable sweat-sensing devices (single-analyte and multi-detection systems) in comparison with our work

\begin{tabular}{|c|c|c|c|c|c|c|c|}
\hline Analyte & Detection method & Electrode material & LOD & Detection range & Sensitivity & Response time & Year \\
\hline Glucose & $\begin{array}{l}\text { Amperometric, } \\
\text { enzymatic (GOx) }\end{array}$ & $\begin{array}{l}\text { rGO on PI with } \mathrm{Au} / \mathrm{Pt} \\
\mathrm{NPs}+\text { chitosan }\end{array}$ & $5 \mu \mathrm{M}$ & $0-2.4 \mathrm{mM}$ & $48 \mu \mathrm{A} / \mathrm{mM} \mathrm{cm}^{2}$ & $20 \mathrm{~s}$ & $2018[48]$ \\
\hline Glucose & $\begin{array}{l}\text { Amperometric, } \\
\text { enzymatic (GOx) }\end{array}$ & \multirow{2}{*}{$\begin{array}{l}\text { SPE, graphite/Ag in } \\
\text { microfluidic PET } \\
\text { patch }\end{array}$} & $11 \mu \mathrm{M}$ & $50-200 \mu \mathrm{M}$ & $1 \mathrm{nA} / \mu \mathrm{M}$ & $1 \mathrm{~min}$ & \multirow[t]{2}{*}{2019 [49] } \\
\hline $\mathrm{K}^{+}$ & $\begin{array}{l}\text { Potentiometric, ISE } \\
\text { (valinomycin) }\end{array}$ & & - & $5-40 \mathrm{mM}$ & $51.3 \mathrm{mV} / \mathrm{dec}$ & - & \\
\hline Glucose & $\begin{array}{l}\text { Amperometric, } \\
\text { enzymatic (GOx) }\end{array}$ & $\begin{array}{l}\text { Photo lithography on } \\
\text { flexible PET; }\end{array}$ & - & $0-200 \mu \mathrm{M}$ & $2.35 \mathrm{nA} / \mu \mathrm{M}$ & $1 \mathrm{~min}$ & \multirow[t]{3}{*}{2016 [29] } \\
\hline $\mathrm{K}^{+}$ & $\begin{array}{l}\text { Potentiometric, ISE } \\
\text { (valinomycin) }\end{array}$ & $\begin{array}{l}\mathrm{Ag} / \mathrm{AgCl} \mathrm{RE} \text { and } \mathrm{CE} \\
\mathrm{PB} / \text { chitosan/CNT on }\end{array}$ & - & $1-32 \mathrm{mM}$ & $61.3 \mathrm{mV} / \mathrm{dec}$ & - & \\
\hline Lactate & $\begin{array}{l}\text { Amperometric, } \\
\text { enzymatic (LOx) }\end{array}$ & $\begin{array}{l}\text { WE; PVB-RE, } \\
\text { carbon/PEDOT:PSS }\end{array}$ & - & $0-30 \mathrm{mM}$ & $220 \mathrm{nA} / \mu \mathrm{M}$ & $1 \mathrm{~min}$ & \\
\hline Lactate & $\begin{array}{l}\text { Amperometric, } \\
\text { enzymatic (LOx) }\end{array}$ & $\begin{array}{l}\mathrm{SPE}, \mathrm{Ag} / \mathrm{AgCl}, \mathrm{CNT} \text {, } \\
\mathrm{TTF} \text {, chitosan, on } \\
\text { temporary tattoo }\end{array}$ & - & Up to $30 \mathrm{mM}$ & $10.31 \mu \mathrm{A} / \mathrm{mM} \mathrm{cm}^{2}$ & $1 \mathrm{~min}$ & $2013[50]$ \\
\hline Lactate & $\begin{array}{l}\text { Amperometric, } \\
\text { enzymatic (LOx) }\end{array}$ & \multirow{2}{*}{$\begin{array}{l}\text { SPE, PB/graphite, } \\
\mathrm{Ag} / \mathrm{AgCl} \text {, carbon, } \\
\text { chitosan }\end{array}$} & $0.39 \mathrm{mM}$ & $0-14 \mathrm{mM}$ & - & $30 \mathrm{~s}$ & \multirow[t]{2}{*}{2017 [34] } \\
\hline $\mathrm{K}^{+}$ & $\begin{array}{l}\text { Potentiometric, ISE } \\
\quad \text { (valinomycin) }\end{array}$ & & $10^{-3.9} \mathrm{M}$ & $0-100 \mathrm{mM}$ & $58.0 \mathrm{mV} / \mathrm{dec}$ & $20 \mathrm{~s}$ & \\
\hline Glucose & $\begin{array}{l}\text { Amperometric, } \\
\text { enzymatic (GOx) }\end{array}$ & LIG, PtNPs, chitosan & $<300 \mathrm{nM}$ & Up to $2.1 \mathrm{mM}$ & $4.622 \mu \mathrm{A} / \mathrm{mM}$ & - & $2020[51]$ \\
\hline Glucose & Amperometric, & \multirow{3}{*}{$\begin{array}{l}\text { All-LIG-based, } \\
\text { drop-coated/- } \\
\text { electrodeposited/- } \\
\text { chemical deposited } \\
\text { Ag/AgCl RE, LIG }\end{array}$} & $13.5 \mu \mathrm{M}$ & Up to $1.5 \mathrm{mM}$ & $20.0 \mu \mathrm{A} / \mathrm{mM} \mathrm{cm}{ }^{2}$ & $60 \mathrm{~s}$ & \multirow[t]{4}{*}{ This work } \\
\hline Lactate & $\begin{array}{l}\text { enzymatic } \\
(\mathrm{GOx} / \mathrm{LOx})\end{array}$ & & $28 \mu \mathrm{M}$ & Up to $5 \mathrm{mM}$ & $16 \mu \mathrm{A} / \mathrm{mM} \mathrm{cm}^{2}$ & & \\
\hline $\mathrm{K}^{+}$ & $\begin{array}{l}\text { Potentiometric, ISE } \\
\quad \text { (valinomycin) }\end{array}$ & & $10^{-4.5} \mathrm{M}$ & Up to $1 \mathrm{M}$ & $96 \mathrm{mV} / \mathrm{dec}$ & $1 \mathrm{~s}$ & \\
\hline Electrolytes & Impedance & $\begin{array}{l}\text { RE possible, } \\
\mathrm{PB} / \text { chitosan WE }\end{array}$ & $10^{-3.5} \mathrm{M}$ & $1 \mathrm{mM}-1 \mathrm{M}$ & - & $5 \mathrm{~s}$ & \\
\hline
\end{tabular}

$G O x$, glucose oxidase; $L O x$, lactate oxidase; $I S E$, ion-selective electrode; $P I$, polyimide; $r G O$, reduced graphene; $N P S$, nanoparticles; $S P E$, screen-printed electrodes; $P E T$, polyethylene terephthalate; $R E$, reference electrode; $C E$, counter electrode; $W E$, working electrode; $P B$, Prussian blue; $C N T$, carbon nanotubes; $P V B$, polyvinyl butyral; PEDOT:PSS, poly(3,4-ethylenedioxythiophene) polystyrene sulfonate; $T T F$, tetrathiafulvalene; $L I G$, laser-induced graphene

Table 2 shows similar sweat-sensing platforms in comparison with important key characteristics of our presented work. Our all-LIG multi-analyte sweat sensor scores well or even better than most comparable works, especially with respect to the simplicity of the fabrication process and the flexibility of introducing new analytes by changing ionophores or enzymes.

\section{Conclusion}

Laser-induced graphene (LIG) is a reasonably new, alternate graphene-like $3 \mathrm{D}$ carbon material investigated for electrochemical sensing, supercapacitors, and fuel cells $[21,27,52]$. Its simple fabrication requires a polyimide foil (such as commercially available Kapton sheets used herein), and a $\mathrm{CO}_{2}$ laser [24]. No additional pastes, substrates, gas environments, cleanroom conditions, or special know-how are needed, which catapults LIG electrodes into a category of most-easy-to-prepare electrochemical transducers from small lab-scale to large-scale production, easily amenable also to roll-to-roll fabrication. In this study, we demonstrated an all-LIG multi-analyte-sensing platform, employing the three relevant electrochemical principles used in point-of-care sensors (i.e., voltammetry, potentiometry, impedance) and addressing a relevant analytical challenge by applying it to sweat analysis. The inherent mechanical flexibility of the LIG substrate paired with the electroanalytical performance of the $3 \mathrm{D}$ graphene-like network enabled the detection of all chosen analytes (electrolyte, potassium ion, glucose, and lactate) in their relevant physiological range. Furthermore, most recent work demonstrated the non-toxicity of the LIG electrodes [53] and previous studies using aptamers indicated that highly sensitive bioanalytical sensors are feasible [21, 54]. Interestingly, when using more advanced substrates, such as polyimide nanofiber mats, new strategies are possible that create nanoparticle-embedding LIG nanofibers [55]. Similar strategies may be feasible when generating 
polyimide-nanoparticle blends and spin-coating those onto flat surfaces prior to pyrolysis via the laser. We predict that LIG electrodes will play a major role in future electroanalytical systems, not only applied to the point-of-care, but also to other low-cost analytical challenges such as food and environmental monitoring, since the all-LIG-sensing platform is feasible and can easily be fabricated even under resource-limited conditions.

Acknowledgments We acknowledge Marcel Simsek for recording the SEM images, Arne Behrent for the Raman measurements, and Vanessa Tomanek for drawing the graphical abstract.

Funding Open Access funding provided by Projekt DEAL. The authors acknowledge partial funding and availability of the laser scriber through a grant by the King Abdullah University of Science and Technology (KAUST) Sensor Initiative (Grant \# CRF-2015-SENSOR-2709).

\section{Compliance with ethical standards}

Conflict of interest The authors declare that they have no conflicts of interest.

Open Access This article is licensed under a Creative Commons Attribution 4.0 International License, which permits use, sharing, adaptation, distribution and reproduction in any medium or format, as long as you give appropriate credit to the original author(s) and the source, provide a link to the Creative Commons licence, and indicate if changes were made. The images or other third party material in this article are included in the article's Creative Commons licence, unless indicated otherwise in a credit line to the material. If material is not included in the article's Creative Commons licence and your intended use is not permitted by statutory regulation or exceeds the permitted use, you will need to obtain permission directly from the copyright holder. To view a copy of this licence, visit http://creativecommons.org/licenses/by/4.0/.

\section{References}

1. Bandodkar AJ, Wang J. Non-invasive wearable electrochemical sensors: a review. Trends Biotechnol. 2014;32:363-71.

2. Tricoli A. Wearable and miniaturized sensor technologies for personalized and preventive medicine. Adv Funct Mater. 2017;27:1-19.

3. Di Sant'Agnese PA, Darling RC, Perera GA, Shea E. Abnormal electrolyte composition of sweat in cystic fibrosis of the pancreas; clinical significance and relationship to the disease. Pediatrics. 1953;12(5):549-63.

4. Mishra A, Greaves R, Massie J. The relevance of sweat testing for the diagnosis of cystic fibrosis in the genomic era. The clinical biochemist. Reviews / Australian Association of Clinical Biochemists. Clin Biochem Rev. 2005;26(4):135-53.

5. Harvey CJ, LeBouf RF, Stefaniak AB. Formulation and stability of a novel artificial human sweat under conditions of storage and use. Toxicol in Vitro. 2010;24(6):1790-6.

6. Vautz W, Seifert L, Mohammadi M, Klinkenberg IAG, Liedtke S. Detection of axillary perspiration metabolites using ion mobility spectrometry coupled to rapid gas chromatography. Anal Bioanal Chem. 2020;412(1):223-32.
7. Jadoon S, Karim S, Akram MR, Kalsoom Khan A, Zia MA, Siddiqi $\mathrm{AR}$, et al. Recent developments in sweat analysis and its applications. Int J Anal Chem. 2015. https://doi.org/10.1155/2015/164974.

8. Anastasova S, Crewther B, Bembnowicz P, Curto V, Ip HM, Rosa $\mathrm{B}$, et al. A wearable multisensing patch for continuous sweat monitoring. Biosens Bioelectron. 2017;93:139-45.

9. Simmers P, Li SK, Kasting G, Heikenfeld J. Prolonged and localized sweat stimulation by iontophoretic delivery of the slowlymetabolized cholinergic agent carbachol. J Dermatol Sci. 2018;89(1):40-51.

10. Moyer J, Wilson D, Finkelshtein I, Wong B, Potts R. Correlation between sweat glucose and blood glucose in subjects with diabetes. Diabetes Technol Ther. 2012;14(5):398-402.

11. Halperin ML, Kamel KS. Potassium. Lancet. 1998;352(9122):135-40.

12. Gengchen L, Smith K, Kaya T. Implementation of a microfluidic conductivity sensor - a potential sweat electrolyte sensing system for dehydration detection. Conference proceedings: ... Annual International Conference of the IEEE Engineering in Medicine and Biology Society. IEEE Engineering in Medicine and Biology Society. Annual Conference 2014:1678-1681.

13. Sakharov DA, Shkurnikov MU, Vagin MY, Yashina EI, Karyakin AA, Tonevitsky AG. Relationship between lactate concentrations in active muscle sweat and whole blood. Bull Exp Biol Med. 2010;150(1):83-5.

14. Soar J, Perkins GD, Abbas G, Alfonzo A, Barelli A, Bierens JJLM, Brugger H, Deakin CD, Dunning J, Georgiou M, Handley AJ, Lockey DJ, Paal P, Sandroni C, Thies K-C, Zideman DA, Nolan JP. European Resuscitation Council Guidelines for Resuscitation 2010 Section 8. 2010:81(10):1400-1433.

15. Ahammad AS, Islam T, Hasan MM. Graphene-based electrochemical sensors for biomedical applications. In: Biomedical Applications of Graphene and 2D Nanomaterials. Amsterdam: Elsevier; 2019. p. 249-82.

16. Brownson DAC, Banks CE, editors. The Handbook of Graphene Electrochemistry: Springer; 2014. -London.

17. Taniselass S, Arshad MKM, Gopinath SCB. Graphene-based electrochemical biosensors for monitoring noncommunicable disease biomarkers. Biosens Bioelectron. 2019;130:276-92.

18. Rakhi RB, Nayak P, Xia C, Alshareef HN. Novel amperometric glucose biosensor based on MXene nanocomposite. Sci Rep. 2016. https://doi.org/10.1038/srep36422.

19. Hammond JL, Formisano N, Estrela P, Carrara S, Tkac J. Electrochemical biosensors and nanobiosensors. Essays Biochem. 2016;60(1):69-80.

20. Zhang C, Zhang Z, Yang Q, Chen W. Graphene-based electrochemical glucose sensors: fabrication and sensing properties. Electroanalysis. 2018;30(11):2504-24.

21. Fenzl C, Nayak P, Hirsch T, Wolfbeis OS, Alshareef HN, Baeumner AJ. Laser-scribed graphene electrodes for Aptamerbased biosensing. ACS Sens. 2017;2(5):616-20.

22. Nayak P, Jiang Q, Kurra N, Wang X, Buttner U, Alshareef HN. Monolithic laser scribed graphene scaffolds with atomic layer deposited platinum for the hydrogen evolution reaction. J Mater Chem A. $2017 ; 5(38): 20422-7$.

23. Nayak P, Kurra N, Xia C, Alshareef HN. Highly efficient laser scribed graphene electrodes for on-chip electrochemical sensing applications. Adv Electron Mater. 2016;2(10):1600185.

24. Lin J, Peng Z, Liu Y, Ruiz-Zepeda F, Ye R, Samuel ELG, et al. Laser-induced porous graphene films from commercial polymers. Nat Commun. 2014;5:5714-22.

25. Cao L, Zhu S, Pan B, Dai X, Zhao W, Liu Y, et al. Stable and durable laser-induced graphene patterns embedded in polymer substrates. Carbon. 2020;163:85-94.

26. Lee S-H, Kim JH, Yoon J-R. Laser scribed graphene cathode for next generation of high performance hybrid supercapacitors. Sci Rep. 2018. https://doi.org/10.1016/j.ijhydene.2018.12.038. 
27. Ye R, James DK, Tour JM. Laser-induced graphene: from discovery to translation. Adv Mater. 2019. https://doi.org/10.1002/adma. 201803621.

28. Aparicio-Martínez E, Ibarra A, Estrada-Moreno IA, Osuna V, Dominguez RB. Flexible electrochemical sensor based on laser scribed graphene/Ag nanoparticles for non-enzymatic hydrogen peroxide detection. Sensors Actuators B Chem. 2019. https://doi. org/10.1016/j.snb.2019.127101.

29. Gao W, Emaminejad S. Fully integrated wearable sensor arrays for multiplexed in situ perspiration analysis. Nature. 2016;529:509-13.

30. Shirreffs SM, Maughan RJ. Whole body sweat collection in humans: an improved method with preliminary data on electrolyte content. J Appl Physiol. 1997;82(1):336-41.

31. Hartig D, Hacke S, Ott L, Gabrielczyk J, Müller C, Jördening H-J, et al. Diffusion studies of glucose and sucrose in chitosan membranes and beads for enzymatic production processes. Chem Eng Technol. 2018;41(7):1433-40.

32. Kang X, Wang J, Wu H, Aksay IA, Liu J, Lin Y. Glucose oxidasegraphene-chitosan modified electrode for direct electrochemistry and glucose sensing. Biosens Bioelectron. 2009;25(4):901-5.

33. Zhu J, Zhu Z, Lai Z, Wang R, Guo X, Wu X, et al. Planar amperometric glucose sensor based on glucose oxidase immobilized by chitosan film on Prussian blue layer. Sensors. 2002;2(4):127-36.

34. Sempionatto JR, Nakagawa T, Pavinatto A, Mensah ST, Imani S, Mercier P, et al. Eyeglasses based wireless electrolyte and metabolite sensor platform. Lab Chip. 2017;17(10):1834-42.

35. Kulkarni T, Slaughter G. Application of semipermeable membranes in glucose biosensing. Membranes. 2016;6(4):55-75.

36. Shiwaku R, Matsui H, Nagamine K, Uematsu M, Mano T, Maruyama Y, et al. A printed organic circuit system for wearable amperometric electrochemical sensors. Sci Rep. 2018. https://doi. org/10.1038/s41598-018-24744-x.

37. Bandodkar AJ, Jia W, Yardımcı C, Wang X, Ramirez J, Wang J. Tattoo-based noninvasive glucose monitoring: a proof-of-concept study. Anal Chem. 2015;87(1):394-8.

38. Lei Y, Zhao W, Zhang Y, Jiang Q, He J-H, Baeumner AJ, et al. A MXene-based wearable biosensor system for high-performance in vitro perspiration analysis. Small. 2019. https://doi.org/10.1002/ smll.201901190.

39. Schmid-Wendtner M-H, Korting HC. The $\mathrm{pH}$ of the skin surface and its impact on the barrier function. Skin Pharmacol Physiol. 2006;19(6):296-302.

40. Derbyshire PJ, Barr H, Davis F, Higson SPJ. Lactate in human sweat: a critical review of research to the present day. J Physiol Sci. 2012;62(6):429-40.

41. Lei Y, Sun R, Zhang X, Feng X, Jiang L. Oxygen-rich enzyme biosensor based on superhydrophobic electrode. Adv Mater. 2016;28(7):1477-81.

42. Khattab TA, Dacrory S, Abou-Yousef H, Kamel S. Smart microfibrillated cellulose as swab sponge-like aerogel for realtime colorimetric naked-eye sweat monitoring. Talanta. 2019. https://doi.org/10.1016/j.talanta.2019.120166.

43. Huang X, Liu Y, Chen K, Shin W-J, Lu C-J, Kong G-W, et al. Stretchable, wireless sensors and functional substrates for epidermal characterization of sweat. Small. 2014;10(15):3083-90.

44. Kim SB, Zhang Y, Won SM, Bandodkar AJ, Sekine Y, Xue Y, Koo J, Harshman SW, Martin JA, Park JM, Ray TR, Crawford KE, Lee K-T, Choi J, Pitsch RL, Grigsby CC, Strang AJ, Chen Y-Y, Xu S, Kim J, Koh A, Ha JS, Huang Y, Kim SW, Rogers JA (2018) Superabsorbent polymer valves and colorimetric chemistries for timesequenced discrete sampling and chloride analysis of sweat via skin-mounted soft microfluidics. Small. 2018; https://doi.org/10. 1002/smll.201703334.

45. Ding R, Lisak G. Sponge-based microfluidic sampling for potentiometric ion sensing. ACA. 2019;1091:103-11.
46. Liu C, Xu T, Wang D, Zhang X. The role of sampling in wearable sweat sensors. Talanta. 2020. https://doi.org/10.1016/j.talanta. 2020.120801 .

47. van Haeringen NJ. Clinical biochemistry of tears. Surv Opthalmol. 1981;26(2):84-96.

48. Xuan X, Yoon HS, Park JY. A wearable electrochemical glucose sensor based on simple and low-cost fabrication supported micropatterned reduced graphene oxide nanocomposite electrode on flexible substrate. Biosens Bioelectron. 2018;109:75-82.

49. Nyein HYY, Bariya M, Kivimäki L, Uusitalo S, Liaw TS, Jansson $\mathrm{E}$, et al. Regional and correlative sweat analysis using highthroughput microfluidic sensing patches toward decoding sweat. Sci Adv. 2019. https://doi.org/10.1098/rsif.2019.0217.

50. Jia W, Bandodkar AJ, Valdés-Ramírez G, Windmiller JR, Yang Z, Ramírez J, et al. Electrochemical tattoo biosensors for real-time noninvasive lactate monitoring in human perspiration. Anal Chem. 2013;85(14):6553-60.

51. Yoon H, Nah J, Kim H, Ko S, Sharifuzzaman M, Barman SC, et al. A chemically modified laser-induced porous graphene based flexible and ultrasensitive electrochemical biosensor for sweat glucose detection. Sensors Actuators B Chem. 2020. https://doi.org/10. 1016/j.snb.2020.127866.

52. Zhang F, Zhang W, Guo J, Lei Y, Dar MA, Almutairi Z, et al. Allcarbon hybrid Mobile ion capacitors enabled by 3D laser scribed graphene. Energy Technol. 2020. https://doi.org/10.1002/ente. 202000193.

53. Puetz P, Behrent A, Baeumner AJ, Wegener J. Laser-scribed graphene (LSG) as new electrode material for impedance-based cellular assays. Sensors Actuators B Chem. 2020. https://doi.org/ 10.1016/j.snb.2020.128443.

54. Yagati AK, Behrent A, Beck S, Rink S, Goepferich AM, Min J, et al. Laser-induced graphene interdigitated electrodes for label-free or nanolabel-enhanced highly sensitive capacitive aptamer-based biosensors. Biosens Bioelectron. 2020. https://doi.org/10.1016/j. bios.2020.112272.

55. Wongkaew N, Simsek M, Arumugam P, Behrent A, Berchmans S, Baeumner AJ. A robust strategy enabling addressable porous 3D carbon-based functional nanomaterials in miniaturized systems. Nanoscale. 2019;11(8):3674-80.

Publisher's note Springer Nature remains neutral with regard to jurisdictional claims in published maps and institutional affiliations.

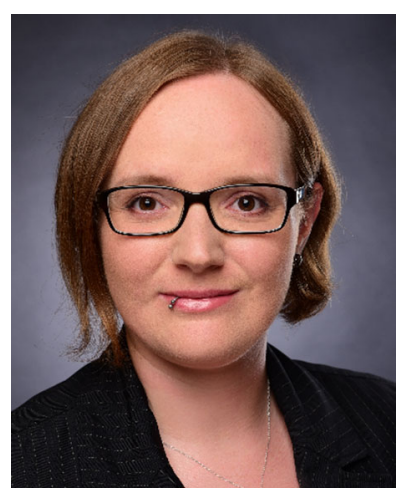

Meike Bauer is a Ph.D. student in Prof. Antje J. Baeumner's group at the Institute of Analytical Chemistry, Chemo- and Biosensors (University of Regensburg). Her research is focused on the development of electrochemical and optical biosensors for point-of-care applications and clinical analysis. 

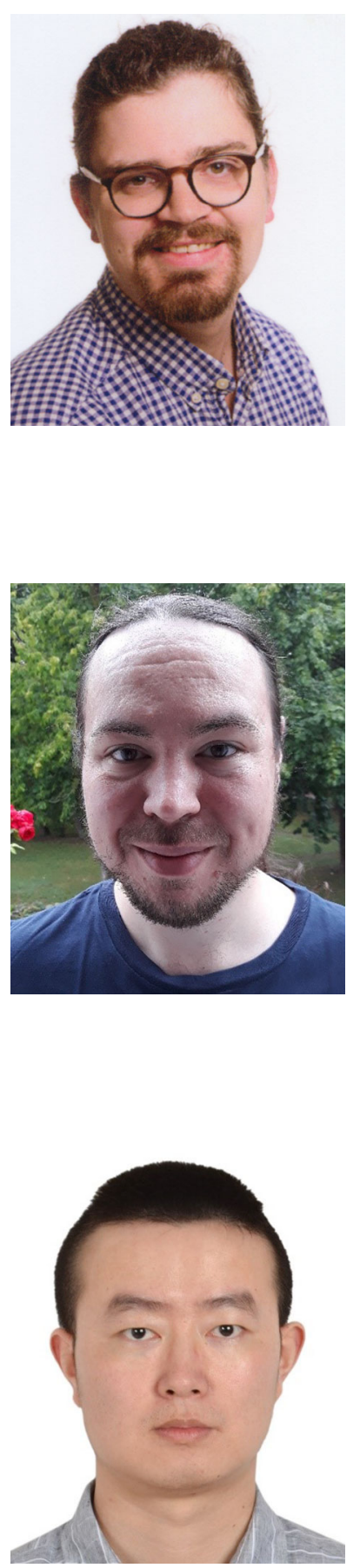

Florian Weinzierl is a Ph.D. student in Prof. Antje J. Baeumner's group at the Institute of Analytical Chemistry, Chemo- and Biosensors (University of Regensburg). His research focuses on the development of microfluidic point-of-care sen-

sors. dent in Prof. Antje J. Baeumner's group at the Institute of Analytical Chemistry, Chemo- and Biosensors (University of Regensburg). In his research, he focuses on the implementation of two-dimensional materials in environmental sensors.

Yongjiu Lei is a Ph.D. student in Prof. Husam Alshareef's group at the Institute of Material Science and Engineering, King Abdullah University of Science and Technology. His research is focused on the development of biosensors and energy storage capacitors.
Lukas Wunderlich is a Ph.D. stu-

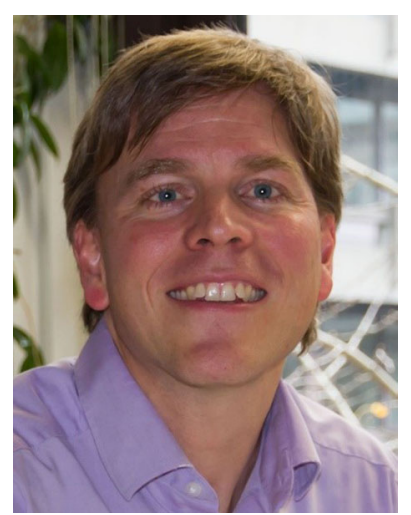

Axel Duerkop is Senior Scientist with a state doctorate at the Institute of Analytical Chemistry, Chemo and Biosensors of the University of Regensburg. His research is devoted to the synthesis and application of chromogenic and/or luminescent probes and materials in assays, sensors, or dipsticks for optical determination of bio-analytes, ions, and food ingredients in real samples.

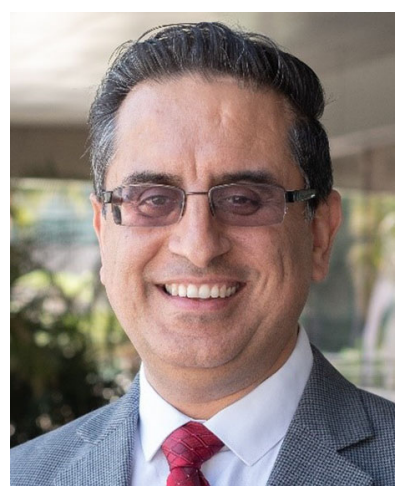

Husam N. Alshareef is Professor of Materials Science and Engineering at KAUST. After nearly 10 years in the semiconductor industry, he joined KAUST in 2009, where he initiated an active research group working on nanomaterial development for energy storage and electronics. $\mathrm{He}$ is a highly cited researcher in materials science, Fellow of the American Physical Society, Fellow of the Royal Society of Chemistry, and IEEE Distinguished Lecturer in

Nanotechnology.

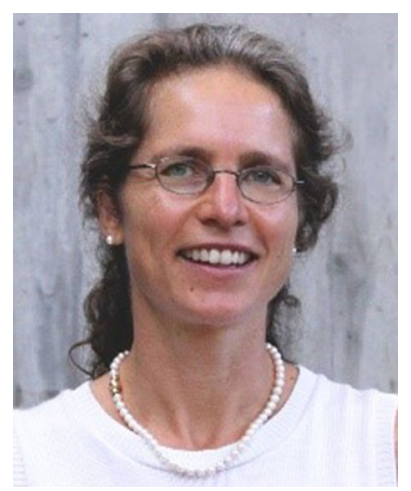

Antje J. Baeumner is Professor and Director of the Institute of Analytical Chemistry, Chemo and Biosensors. Before joining the University of Regensburg in 2013, she was Full Professor in the Dept. of Biological and Environmental Engineering at Cornell University, Ithaca, NY. Her research focuses on the development of biosensors, bioanalytical microsystems, and point-of-care systems for the detection of toxins, pathogens, and clinical analytes. 